\title{
Considerations on the caliher of the internal iliac vein
}

\author{
Discipline of anatomy, Department I - preclinical disciplines, Faculty of medicine, University "Ovidius" \\ Constanţa
}

\begin{abstract}
The diameter at the origin of the internal iliac vein was found between 4.7 to $9.9 \mathrm{~mm}$; for the right internal iliac vein between 4.7 to $9.7 \mathrm{~mm}$; the statistical distribution groups value in ascending order being as follows: 4.7 to $5.5 \mathrm{~mm}$ : 4 cases (22.22\% of cases); 6.9 to 7.8 mm: 6 cases (33.33\% of cases); 8.4-8.8 mm: 4 cases (22.22\% of cases); 9.1 to $9.7 \mathrm{~mm}: 4$ cases $(22.22 \%$ of cases). The diameter at the origin of the left internal iliac vein was between 4.8 to $9.9 \mathrm{~mm}$, while the distribution statistics on groups of values, in ascending order, being as follows: $4.8-5.2 \mathrm{~mm}: 4$ cases (22.22\% of cases); 6.8-7.1 mm: 8 cases (44.44\% of cases); 8.3 to $9.9 \mathrm{~mm}$ : 6 cases $(33.33 \%$ of cases). The diameter at the end of the internal iliac vein was between 5.9 to $10.2 \mathrm{~mm}$; the diameter at the end of the right internal iliac vein was between 6.1 to $10.2 \mathrm{~mm}$, the statistical distribution of values groups in ascending order being follows: 6.1 to $7.5 \mathrm{~mm}$ : 6 cases $(33.33 \%$ of cases); 8.4 to $8.7 \mathrm{~mm}$ : 8 cases ( $44.44 \%$ of cases); 9.3 to $10.2 \mathrm{~mm}$ : 4 cases (22.22\% of cases). The diameter at the end of the left internal iliac vein was between 5.9 to $9.9 \mathrm{~mm}$, while the distribution statistics on groups of values in ascending order being as follows: 5.9 to $6.2 \mathrm{~mm}: 4$ cases (22.22 $\%$ of cases); 7 to $7.6 \mathrm{~mm}$ : 3 cases ( $16.67 \%$ of cases); 8.3-8.4 mm: 5 cases (27.28\% of cases); 9.1 to $9.9 \mathrm{~mm}$ : 6 cases ( $33.33 \%$ of cases). Comparing the common iliac Iliescu D.M.
\end{abstract}

Department of Anatomy, Faculty of medicine, University "Ovidius" Constanța, Romania

Aleea Universitatii, Nr. 1, Campus B

Constanţa, România

dan@anatomie.ro vein caliber of the two, right and left, we found that in 10 cases (55.56\% of cases), the right internal iliac vein has a greater diameter than the left one by $0.3 \mathrm{~mm}$. In 8 cases ( $44.44 \%$ of cases), the left internal iliac vein has a larger diameter than the right one with 0.1-0.6 mm; between the two values there is a difference of $0.5 \mathrm{~mm}$

Keywords: internal iliac veins, termination, morphometry.

\section{Introduction}

According to [1 and 2], the internal iliac vein corresponds, through the path and its collateral branches, exactly on the accompanying artery. It originates at the top of the greater ischiadic notch, where they are headed higher and to the upper part of the appropriate sacroiliac joint, making anastomosis with the external iliac vein on the same side, forming the corresponding common iliac vein. It has an average length of $4 \mathrm{~cm}$, with its $8-10 \mathrm{~mm}$ diameter $[1,2]$.

According to [3], the internal iliac vein is formed by veins which converge superior in the greater ischiadic notch, ascends postero-medially to the internal iliac artery to encounter the external iliac vein, with whom form the common iliac vein, before the lower portion of the sacro-iliac joint. It is covered anterior-medial by parietal peritoneum. 
[4] considers that the internal iliac vein is a true inferior caval venous system, infusing it through the three varieties of the venous branches the lower limb, rachis and genitourinary and digestive viscera.

For [5] the internal iliac vein is voluminous and very short, as the satellite arterial trunk, located laterally to the artery on the right side and posterior superior on the left side. Right confluence of the internal and external iliac vein is anterior-inferior to the corresponding common iliac artery bifurcation, located in the arterial bifurcation angle. On the left, the confluence may be covered by the internal iliac artery, when the origin of the two iliac arteries (internal and external) from common iliac are adjacent to each other. The internal iliac vein is without valves and sometimes it can be duplicated. According to [6], the internal iliac vein has a length of $4 \mathrm{~cm}$.

\section{Materials and methods}

The internal iliac vein caliber resulted from a larger study done on iliac veins (common external and internal), made on a number of 82 cases, of which 38 dissections, 12 Doppler ultrasound, 18 cavographies and 14 angioCT's. We had no case of plastic injection in the iliac veins. To these are added also 4 cases of iliac vessels (artery and vein), harvested from fresh cadavers, on which were studied the structure of the vascular wall. The Color Doppler ultrasounds were performed on young, healthy subjects (students from the Faculty of Medicine), on GE Voluson E8 and Expert device. The cavographies that we studied are part of the anatomy laboratory collection of the Faculty of Medicine of the University "Ovidius". AngioCT sites that we had the opportunity to examine them come from Diagnostic Center Pozimed Constanta, being performed on a GE LightSpeed CT VCT64 Slice CT. The caliber of the internal iliac vein being studied only on a total of 18 cases, it was not possible to assess its distribution on gender, making only a comparison of the right and left internal iliac vein caliber.

\section{Results and discussion}

The origin diameter of the internal iliac vein was found between 4.7 to $9.9 \mathrm{~mm}$, the diameter at the origin of the right internal iliac vein was between 4.7 to $9.7 \mathrm{~mm}$, and the distribution statistics on groups of values being the following:

- 4.7-5.5 mm: 4 cases (22.22\% of cases);

- 6.9-7.8 mm: 6 cases (33.33\% of cases);

- 8.4-8.8 mm: 4 cases (22.22\% of cases);

- 9.1-9.7 mm: 4 cases (22.22\% of cases).

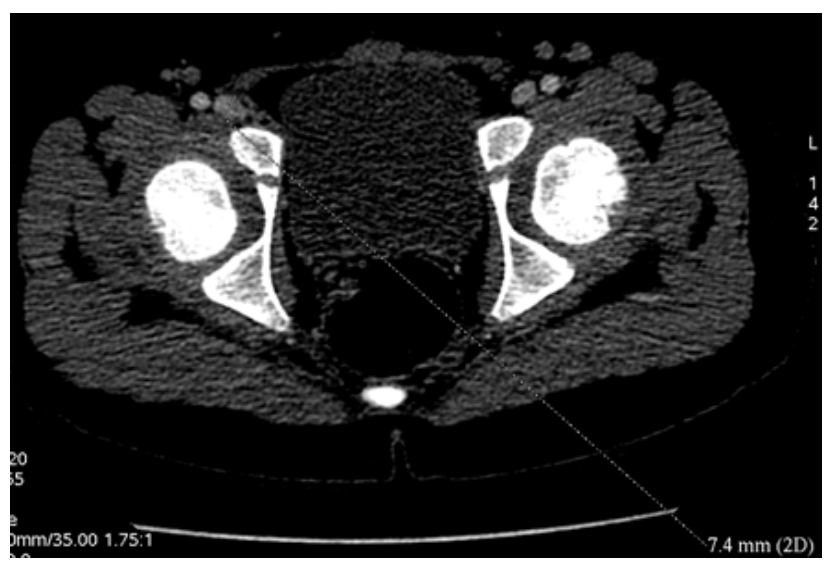

Figure 1 - Right internal iliac vein in females with a size of $4.7 \mathrm{~mm}$ at origin.

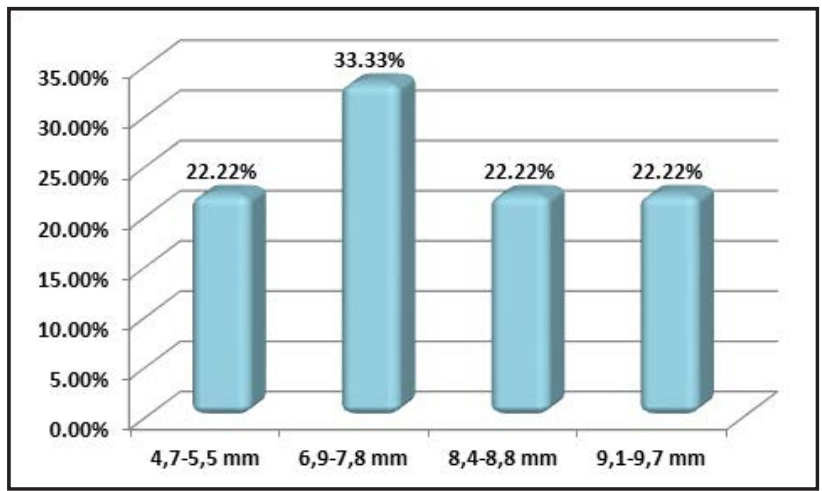

Figure 2 - The at diameter origin - values of the right internal iliac vein

It appears that on the right internal iliac vein, between the minimum and maximum origin diameter there is a difference of $5 \mathrm{~mm}$. Most cases, 10 cases 
(55.56\% of cases) showed a caliber between 6.9 to $8.8 \mathrm{~mm}$, the difference between the minimum and maximum diameter being of $1.9 \mathrm{~mm}$.

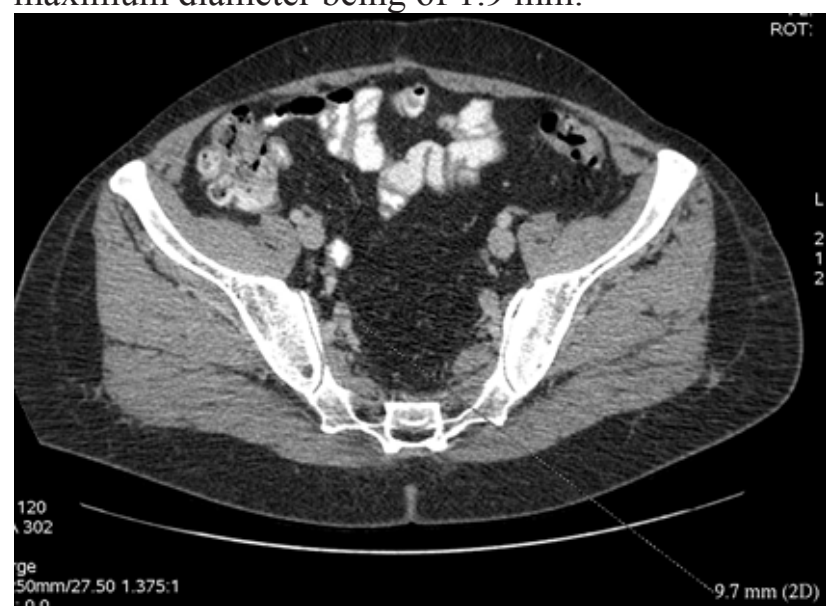

Figure 3 - Right internal iliac vein in females with a caliber of $9.7 \mathrm{~mm}$ at origin.

The diameter at origin of the left internal iliac vein was found between 4.8 to $9.9 \mathrm{~mm}$, the distribution statistics on groups showing the following values, in ascending order:

- 4.8-5.2 mm: 4 cases (22.22\% of cases);

- 6.8-7.1 mm: 8 cases ( $44.44 \%$ of cases);

- 8.3-9.9 mm: 6 cases (33.33\% of cases).

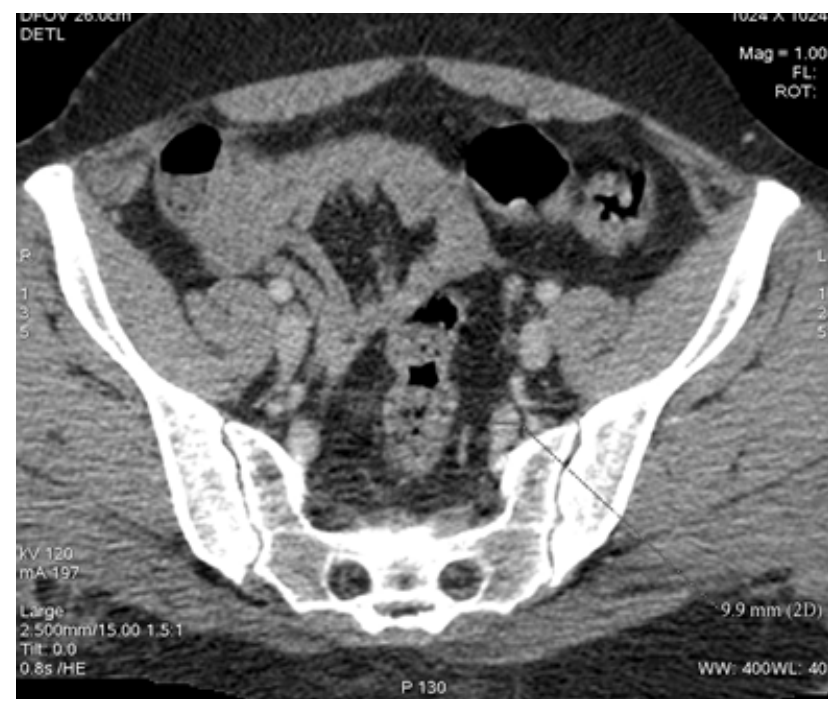

Figure 4 - Left internal iliac vein in males with a caliber of $9.9 \mathrm{~mm}$ at origin.
It appears that to the left internal iliac vein, between the minimum and maximum origin diameter there is a difference of $5.1 \mathrm{~mm}$. Most cases, 8 cases (44.44\% of cases), presented a caliber between 6.8 $7.1 \mathrm{~mm}$, the difference between the minimum and maximum diameter being $0.3 \mathrm{~mm}$

The diameter at the end of the internal iliac vein was found between 5.9 to $10.2 \mathrm{~mm}$, at the end of the right internal iliac vein found him between 6.1 to $10.2 \mathrm{~mm}$, and the statistical distribution of values groups in ascending order being as follows:

- 6.1-7.5 mm: 6 cases (33.33\% of cases);

- 8.4-8.7 mm: 8 cases (44.44\% of cases);

- 9.3-10.2 mm: 4 cases (22.22\% of cases).

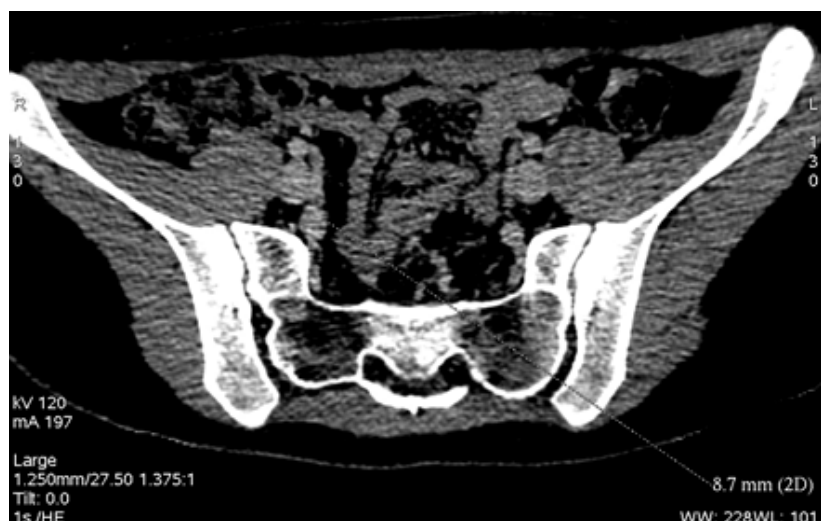

Figure 5 - Right internal iliac vein in females with a caliber of $8.7 \mathrm{~mm}$ at the end.

It appears that to the right internal iliac vein, between the minimum and maximum end diameter there is a difference of $4.1 \mathrm{~mm}$. Most of the cases, 8 cases ( $44.44 \%$ of cases) showed a caliber between 8.4 to $8.7 \mathrm{~mm}$, the difference between the minimum and maximum diameter being $0.3 \mathrm{~mm}$

The diameter at the end of the left internal iliac vein was found between 5.9 to $9.9 \mathrm{~mm}$, distribution statistics on groups of values in ascending order being follows:

- 5.9-6.2 mm: 4 cases (22.22\% of cases);

- 7-7.6 mm: 3 cases ( $16.67 \%$ of cases);

- 8.3-8.4 mm: 5 cases (27.28\% of cases);

- 9.1-9.9 mm: 6 cases (33.33\% of cases). 


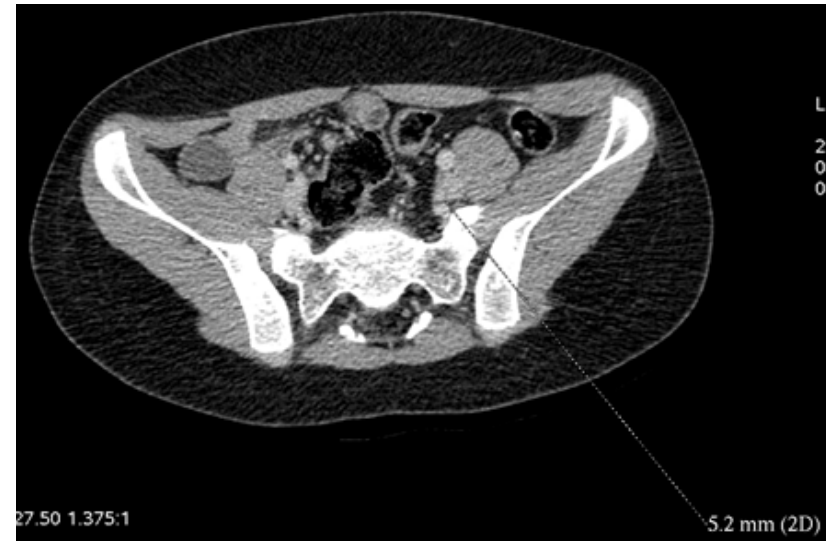

Figure 6 - Left internal iliac vein in males with a caliber of $5.9 \mathrm{~mm}$ at the end.

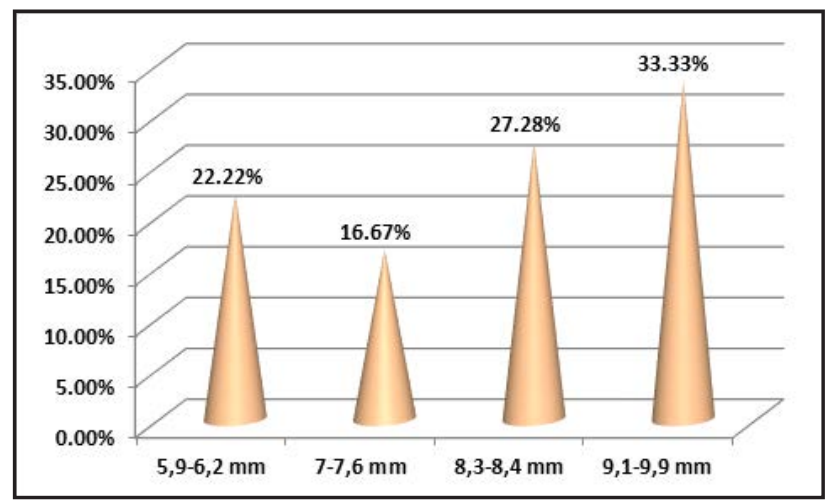

Figure 7 - Values of the end diameter of the left internal iliac vein

It is noted that to the left internal iliac vein, between the minimum and maximum diameter there is a difference of $4 \mathrm{~mm}$, greater than to the right internal iliac vein by $1.4 \mathrm{~mm}$. Most cases, 11 cases (61.11\% of cases), have a caliber between 8.3 to $9.9 \mathrm{~mm}$, the difference between the minimum and maximum diameter is $1.6 \mathrm{~mm}$

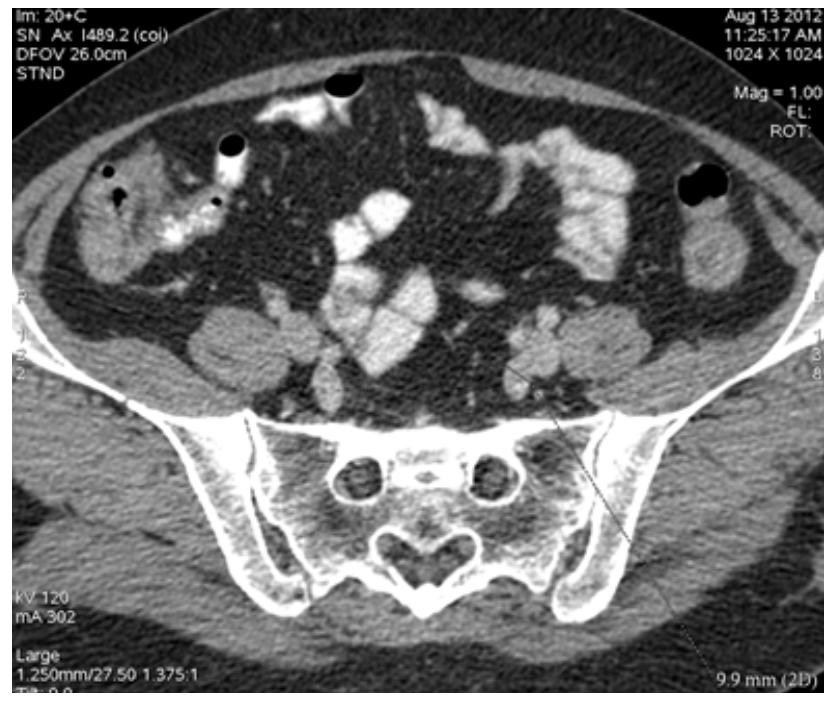

Figure 8 - Left internal iliac vein in females with a diameter of $9.9 \mathrm{~mm}$ at the end.

Comparing the two, right and left, common iliac vein caliber, we found that in 10 cases $(55.56 \%$ of cases), the right internal iliac vein has a greater diameter than the left by $0.3 \mathrm{~mm}$.

In 8 cases $(44.44 \%$ of cases $)$, the left internal iliac vein has a larger diameter than the right with 0.1 $0.6 \mathrm{~mm}$, between the two values existing a difference of $0.5 \mathrm{~mm}$

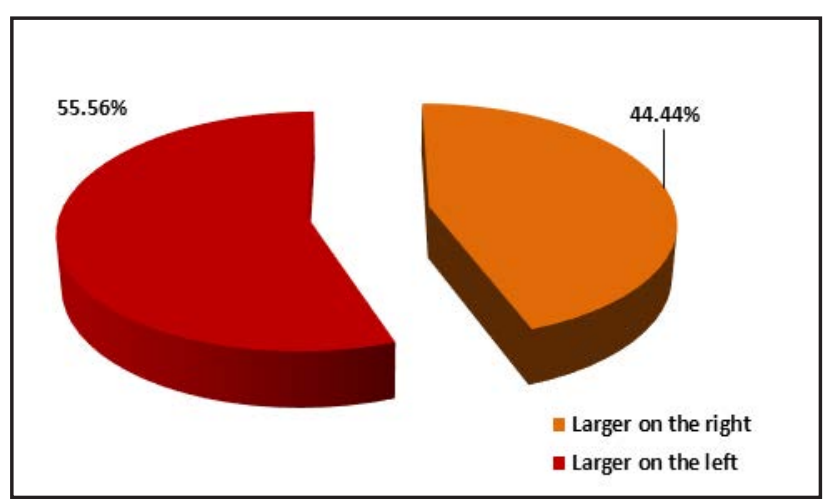

Figure 9 - External iliac vein diameter, comparison right/ left 


\section{Conclusions}

The differences of the caliber at the origin and at the end of the internal iliac veins are $1.2 \mathrm{~mm}$ for the minimum diameter and lower for maximum diameter, being only $0.3 \mathrm{~mm}$. For the right iliac vein the difference at the origin between the minimum caliber is $1.4 \mathrm{~mm}$ and for the left one is $0.9 \mathrm{~mm}$. Regarding the maximum caliber, the difference between the origin and the end is $0.3 \mathrm{~mm}$ on the right internal iliac vein and for the left internal iliac vein, on each side, was the same as the maximum diameter $(9.9 \mathrm{~mm})$. The minimum origin diameter was higher on the left by $0.1 \mathrm{~mm}$ and $0.2 \mathrm{~mm}$ for maximum diameter of the right one. Upon termination, the internal iliac vein minimum diameter was larger on the right with 0.2 $\mathrm{mm}$ and maximum diameter was still larger on the right by $0.3 \mathrm{~mm}$.

\section{References}

1. Testut, L. (1921). Traité d'anatomie humaine. Angéiologie, livre IV, (pp. 316-318). Paris: Ed. Gaston Doin

2. Testut, L. (1924). Traité d'anatomie humaine. Angéiologie, livre IV, (pp. 710-714). Paris: Ed. Gaston Doin

3. Gray's Anatomy. (1995). Thirty-eighth edition. (pp. 1598-1599). New York: Ed. Churchill Livingstone

4. Gillot, C. (1994). Le système cave infèrieure. In: Chevrel, J.P. Anatomie clinique. Le tronc. (pp. 441-448). Paris: Ed. Springer Verlag

5. Rouvière, H. \& Delmas, A. (1997). Anatomie Humaine déscriptive topographique et fonctionnelle. Tome 2.14-edition, (pp. 217-225). Paris: Ed. Masson

6. Wikipedia, from: http://de.wikipedia.org/wiki/ vena iliaca interna
7. ****** Terminologia Anatomica. International Anatomical Terminology. (1988). Federative Committee on Anatomical Terminology. (pp. 97). Stuttgart: Thieme Verlag 